\title{
O papel dos contratos e das ações coletivas na produção e comercialização do milho em Moçambique
}

César Benites Mário Zidora cesarzidora@yahoo.com.br Universidade Estadual do Oeste do Paraná, Toledo, Paraná, Brasil

Weimar Freire da Rocha Jr wrochair2000@gmail.com

Universidade Estadual do Oeste do Paraná, Toledo, Paraná, Brasil

\section{Marcia Carla Pereira Ribeiro}

mcarlaribieiro@uol.com.br

Univerisdade Federal do Paraná, Curitiba, Paraná, Brasil

\section{Débora da Silva Lobo}

dslobo@uol.com.br Paraná, Toledo, Paraná, Brasil

Homero Fernandes Oliveira homero2@uol.com.br Universidade Estadual do Oeste do Paraná, Toledo, Paraná, Brasil

\section{RESUMO}

A pesquisa teve como objetivo central analisar o papel dos contratos e das ações coletivas na produção e comercialização do milho em Moçambique. Metodologicamente a pesquisa foi qualitativa e contou com o uso de dados secundários (revisão da literatura) e ainda dados primários e contou com uma amostra de 107 produtores de milho das zonas rurais. Quanto ao objetivo, foi explicativa e descritiva. O Resultado da pesquisa evidenciou que o uso de contratos e das ações coletivas constituem estruturas de governança eficientes ao produtor porque agregavam valor à produção e benefícios coletivos de natureza econômica quando comparado a título individual. A renda bruta da produção de milho foi maior em produtores que estavam organizados em ações coletivas e para os que comercializavam via contratos. As ações coletivas e o uso de contratos criam acesso aos produtores a novos mercados, ao crédito e na agregação do valor a produção.

PALAVRAS-CHAVE: ações coletivas, contratos de produção e comercialização do milho. 


\section{INTRODUÇÃO}

Segundo a African Bank ofDevelopment "ABD" (2000) e FoodAndAgricultureOrganizationsOf The United Nations "FAO" (2011) a agricultura é uma atividade econômica de destaque em Moçambique, com uma empregabilidade de $80 \%$ da população rural e responde por $23 \%$ do PIB do país.

De mais a mais, Moçambique possui aproximadamente 36 milhões de hectares de terra arável, dos quais apenas 5,7 milhões de hectares são ocupados por mais de 3,7 milhões de pequenas e médias propriedades. Cerca de $70 \%$ de toda a terra cultivada é ocupada por pequenas propriedades, com tamanho médio de dois hectares, mais conhecidas por machambas (unidades de produção agrícola). Os principais produtos agrícolas de Moçambique são o milho, o arroz, a mandioca e as hortaliças.

A produção de milho ocupa primeiro lugar em termos de produção e comercialização, constituindo a base alimentar para os mais de 28 milhões de pessoas. O cultivo do milho é desempenhado pelo pequeno agricultor, que se sustenta para garantir alimento para seu núcleo familiar e na geração de renda como forma de suprir as demais necessidades da família: na educação dos filhos, construção de uma moradia condigna, e melhoria da qualidade de vida

No entanto, os produtores rurais em Moçambique têm sofrido com os problemas que ocorrem ao longo da cadeia produtiva do milho tais como: acesso à mercados alternativos para a comercialização da produção, assimetria de informações sobre preço de insumos e a produção propriamente dita, existência de poucas associações e cooperativas, presença de intermediários, que se valem das assimetrias informacionais e têm atitudes oportunistas, ausência de plataformas tecnológicas para a gestão de informação agrícola, infraestrutura logística deficiente para escoamento da produção (BANCO MUNDIAL, 2016; FAO, 2015; USAID, 2015).

Apesar das dificuldades e para atenuar os problemas supracitados, os produtores tentam se organizam em associações e cooperativas agrárias, para traçar estratégias coletivas para suprimir ou amenizar os obstáculos sofridos no processo na produção e comercialização do milho e ainda agregar valor à produção. Segundo o Serviço Nacional de Aprendizagem Rural "SENAR" (2011), o princípio do associativismo e cooperativismo constituem ações coletivas de relevância aos produtores rurais, uma vez que na atuação conjunta gera-se um sinergismo para promover as mudanças em prol do grupo, pelo compartilhamento de informações e solidariedade que geram as mudanças que se traduzem em um conjunto de benefícios coletivos superiores aos individuais e pela ótica econômica proporciona a agregação de valor da produção e viabiliza a atividade pela melhoria do sistema.

Para além de organizarem-se em ações coletivas na busca de soluções relacionados com a produção e comercialização agrícola, os produtores também fazem o uso de contratos agrícolas na produção e comercialização do milho. A adoção de contratos por parte dos produtores em Moçambique é uma prática nova que atrai muitos produtores agrícolas não só na cultura do milho, mas também em culturas como hortaliças, arroz e cana de açúcar.

O contrato ao produtor constitui-se em uma das diversas alternativas na promoção, na agregação de valor e ainda na melhor inserção da agricultura 
familiar nos mercados na busca de melhor eficiência ao longo da cadeia produtiva. Já as ações coletivas podem melhorar a formalização de alianças estratégicas entre os produtores, quer seja horizontalmente e verticalmente, que se mostra como uma forma socioeconômica bem eficiente para suprir o papel institucional garantindo o bem estar social (PREZOTTO, 2016; ZYLBERSZTAIJN, 2005).

Dada a relevância do milho para a economia de Moçambique, seria pertinente entender de forma sistêmica como todas as atividades socioeconômicas ocorrem desde o processo de produção e de comercialização, suas relações entre os stakeholder, que proporcionam agregar valor. Neste sentido, o objetivo central desta pesquisa é analisar o papel e os benefícios do uso dos contratos e das ações coletivas na produção e comercialização do milho em Moçambique.

A pesquisa está dividida em cinco seções centrais: inicialmente, a introdução, a segunda a revisão da literatura seção que contém abordagens teóricas que sustentam a pesquisa como, por exemplo, a caracterização da agricultura de Moçambique, aspectos teóricos relacionados com os contratos e ações coletivas, a terceira constitui a metodologia do trabalho em que se aborda a elaboração da pesquisa, e a quarta parte trata dos benefícios das ações coletivas e contratos na produção e comercialização do milho e, por fim, a quinta parte que corresponde às considerações finais pesquisa.

\section{REVISÃO DE LITERATURA}

Esta seção irá se pautar em dois elementos teóricos sobre as ações coletivas e os contratos.

\section{Teoria de ações coletivas e sua importância}

Segundo Olson (1999), na teoria econômica apresenta-se que as ações coletivas surgem como estratégia aos indivíduos, pois vislumbram que os ganhos conjuntos superam ações individuais. No entanto, aponta que avaliando as vantagens de agir coletivamente a fim de atingir um objetivo comum, ainda assim existem indivíduos que possam demonstrar falta de disposição em cooperar, mais tolerante em grupos grandes, que são denominados pelo autor como freeriders, pois muitas vezes não se esforçam e vão de carona na ação de outrem, e por vezes podem inibir ou causar desmotivação na ação do grupo.

Em ações coletivas existe cooperação entre os agentes envolvendo uma negociação do tipo ganha-ganha, buscando metas a serem alcançadas em conjunto, foco em longo prazo e maximização conjunta de resultados beneficiando todos os atores envolvidos (OLSON, 1999).

Para SENAR (2011, p. 14-15), agir coletivamente significa conquistar mais poder de influir. Através da associação, os produtores e trabalhadores podem resolver coisas por eles mesmos e outras que precisam ser buscadas fora. Ao conquistar os propósitos desejados, as pessoas sentem-se estimuladas, a confiança entre elas aumenta e, ação coletiva, passa a ser percebido como uma conquista do grupo. 
As pessoas, por meio de sua organização em associações rurais, podem realizar transformações sociais, políticas e econômicas. As transformações sociais podem ser sentidas a partir da melhoria das condições de vida, trabalho, estudo, lazer, cultura, na comunidade.

Granovetter (1983), ressalva o risco das ações coletivas quando aborda a questão dos grupos homogêneos (laços fortes) e heterogêneos (laços fracos). Segundo o autor, a formação e a manutenção de grupos heterogêneos é marcada por um alto nível de conflito mútuo, o que ocorre em função das acentuadas diferenças existentes entre os indivíduos de grupos heterogêneos. Os laços fracos, agregam maior valor à ação conjunta, isso por serem compostos por membros, muitas vezes, desconhecidos e com ideias e experiências diversas, o que favorece a inovação. Por outro lado, os laços fortes possuem menos conflitos, mas agregam pouco valor, uma vez que, por serem formados por membros pertencentes a um mesmo círculo social, dispõem das mesmas informações e recursos existentes.

Em ações coletivas os grupos agem com intuito de promover interesses conjuntos, cujo alicerce são normas e regras funcionais guiadas pela confiança, reciprocidade e reputação entre os agentes envolvidos. Os membros de um grupo ou ação coletiva irão trabalhar em conjunto para trazer a solução de um problema que feito em singular seria difícil de alcançar. Dentro do grupo também estariam indivíduos oportunistas que agirão em prol de interesses individuais em detrimento dos outros (OLSON, 1999).

Ostrom (2007) reconheceu que em ação coletiva é preciso reconhecer as ligações complexas entre variáveis em vários níveis que, em conjunto, afetam a reputação individual, confiança e reciprocidade, pois estes, por sua vez, afetam níveis de cooperação e benefícios conjuntos. Ponderou ainda que ao invés de olhar para todas as variáveis potenciais, é preciso focar em uma definida, na estreita cadeia de relacionamentos.

Em ações coletivas há sempre umambiente complexo que conta com a heterogeneidade dos participantes, havendo um ou alguns indivíduos com interesses mais fortes na obtenção de um bem público. Muitos argumentos apontam para heterogeneidade como uma séria dissuasão para a cooperação. Torna-se mais eficiente na busca de solução conjunta em ações coletivas à existência de grupos menores e heterogêneos. Os grupos menores têm maiores vantagens que os grandes porque facilitam o controle dos membros, e a opinião ou contribuição de cada é bem vinda e de maior apreço, cria-se barreiras de existência de indivíduos, como efeito carona ou freeriders(OSTROM, 2007).

Entretanto, a organização de ações coletivas, justamente por se tratarem de formas complexas, e eficientes na busca de soluções conjuntas, também apresenta dificuldades, riscos e custos, quer no âmbito da sua formação ou mesmo na monitoria das atividades. Nesse sentido, Olson (1999) aborda que: i) indivíduos racionais e centrados nos próprios interesses não agirão para promover interesses comuns ou grupais a menos que exista algum incentivo à parte do benefício coletivo ou alguma coerção para forçá-lo a cooperar; ii) existem dificuldades na coordenação de ações coletivas realizadas em grupos grandes; iii) há a presença de custos de organização, que são uma função crescente do número de indivíduos no grupo; iv) há a presença de freeriders, indivíduos que não auxiliam na cooperação, mas que usufruem do esforço e resultado obtido coletivamente. 


\section{Teoria de contratos e sua relevância para o setor agrícola}

Por natureza os produtos agrícolas possuem certas peculiaridades: são perecíveis, dependem das condições climáticas para sua produção, necessitam por vezes de uma padronização quanto à comercialização, que se destina ao mercado internacional. Pelas características da atividade agrícola vários fatores tornam a atividade susceptível a riscos na:produção (biológicos, climáticos etc.) e comercialização (sazonalidade de preços, estoques etc.), sendo assim necessária a elaboração de contratos como estrutura de governança ideal para coordenar o processo(ALLEN; LUECK, 2002, 2005).

O contrato agrícola pode ser definido como uma estrutura de governança, na qual o produtor se compromete(concorda em vender/entregar a sua produção dentro de um conjunto de procedimentos e normas estabelecidas de livre vontade entre produtor e um potencial comprador, que pode ser individual ou mesmo uma firma processadora de produtos agrícolas, sendo pago de acordo com clausulas apresentadas no contrato (FAO, 2001; SHEPHERD, 2013; KUNKEL et al, 2015).

A estrutura de governança contrato na agricultura deve ser visto como uma opção que pode ser estabelecida entre as partes (agroindústria e produtor rural) com o objetivo de mitigar os custos de transação. Para ser bem sucedido, requer um compromisso de ambas as partes, ou seja, deve se criar um ambiente de confiança que promova a manutenção do pacto estabelecido nas cláusulas presentes no contrato. Da mesma forma, as partes devem honrar o que foi estabelecido e se adequar as exigências contratuais de forma a evitar ações oportunistas. O comprometimento entre as partes em honrar o que foi estabelecido no processo de negociação é o motivo impulsionador do bom relacionamento e benefício a longo prazo (FAO, 2001; VAVRA, 2009).

Pela estrutura de governança contrato é factível adotar soluções que aperfeiçoem as relações entre as partes, as quais reduzam os custos de transação, garantindo maior eficiência no mercado. No entanto, a solução ofertada pela legislação caso ocorra o descumprimento das cláusulas contratuais, que é pela indenização, não se mostrará um instrumento efetivo para a coibição de situações oportunistas que possam ser adotadas pelas partes contratantes (RIBEIRO; ROCHA; CZELUSNIAK, 2017).

Os contratos são cada vez mais requisitados no agronegócio da produção agrícola ao marketing, podendo ser natureza: arrendamentos de terra, contratos de escritura, contratos de produção e comercialização, notas e garantias, hipotecas e contratos de Escritura e locações de fazendas, aluguel de máquinas, mão de obra, de infraestruturas de armazenamento da produção, contratos de prestação de serviços, cuja essência de cada contrato baseada na reputação entre os agentes (ALLEN; LUECK, 2002, 2005; KUNKEL et al, 2015).

$\mathrm{Na}$ agricultura, os contratos estabelecem relações mutuamente benéficas entre processadores e produtores, em última análise, abordam as restrições do mercado e as funções de suporte com desempenho inferior que resultam em qualidade e quantidade de produtos. Dadas as relações fracas entre os produtores e o mercado nos setores de culturas selecionadas, o acordo de subcontratação é utilizado para estimular uma situação ganha-ganha isto é como resultado de uma cooperação. Assim, os produtores podem, em parte, acessar 
serviços e insumos de crédito, enquanto os compradores conseguem consolidar com mais facilidade os volumes necessários e a qualidade da matéria-prima para alimentar suas operações e alcançar novos mercados (RLDC, 2016).

A elaboração de contratos bem organizados possibilita ao produtor contornar obstáculos e buscar eficiência em todo processo produtivo tornando a atividade produtiva economicamente rentável. Por outro lado os contratos também podem oferecer aos investidores a oportunidade de garantir uma fonte confiável de fornecimento, desde a perspectiva da quantidade e da qualidade (FAO, 2001). Segundo Zylbersztajn (1995) a escolha dos contratos se fundamenta na maior eficiência nos sistemas agroindustriais pela mediação de conflitos entre aos agentes envolvidos o que implicará na redução de custos de transação decorrentes em todo processo produtivo. Segundo Farina; De Azevedo; Saes (1997), por custos de transação entende-se como os custos que indiretamente estejam ligados a produção que surgem na medida em que os agentes estabelecem uma relação entre si, no qual problemas sobre a coordenação das ações emergem.

Os contratos em geral, independentemente da atividade ou setor são elaborados para mediar e resolver a disputa de conflitos entre os agentes envolvidos em uma negociação. Os agentes envolvidos em uma transação são guiados por dois pressupostos comportamentais: a racionalidade limitada e o oportunismo. Os agentes são racionais e essa racionalidade é limitada devido à circunstancias cognitivas que limitam a percepção e entendimento dos agentes e das incertezas existentes no ambiente econômico, caracterizando assim a incompletude dos contratos elaborados, os quais dificultando a previsão de situações futuras em uma negociação estabelecida. Existe, porém, o comportamento oportunista caracterizado pela manipulação da informação com objetivos de tirar proveitos e ganhos indevidos, causando prejuízos de natureza econômica sobre outro agente envolvido no processo (WILLIAMSON, 1991; ZYLBERSZTAJN, 1995; FANI, 2013).

Para além dos pressupostos comportamentais, existem três característicasque dimensionalizam as transações que são a: especificidade de ativos, frequência e incerteza. Esses três elementos definem a estrutura de governança adota pela redução dos custos de transação (WILLIAMSON, 1991). Os contratos do agronegócio cumprem a função de gerar estabilidade nas relações e promover a redução dos custos de transação, mesmo existindo lacunas para práticas oportunistas dado ao conjunto complexo de relações existente no ambiente econômico e a racionalidade limitada dos agentes apresentados anteriormente.

A partir da próxima seção serão apresentadas as evidências empíricas constatadas na agricultura moçambicana.

\section{Características da agricultura em Moçambique}

A agricultura em Moçambique constitui um setor de economia fundamental para o bem estar social, o seu contributo no PIB é 23\% (MINISTÉRIO DE AGRICULTURA E SEGURANÇA ALIMENTAR-MASA, 2015). A população básica de sobrevivência para a geração de renda e no contributo da segurança 
alimentar.

Segundo o INE (2011), MASA (2017), estima-se que a produção agrícola envolva cerca de 3,7 milhões de pequenos produtores, 24.448 médios produtores e 827 grandes produtores. Em termos da área total de produção de 5,4 milhões de hectares, $85 \%$ que corresponde a uma área de 4,59 milhões é atribuída ao pequeno produtor familiar. Os restantes $15 \%$ (0,81 milhões), são atribuídos aos médios e grandes produtores que se concentram mais nas culturas de rendimento e de exportação.

A área cultivada do produtor familiar em Moçambique tem sido em média menor do que cinco hectares sendo a agricultura meramente de subsistência, composta basicamente de culturas alimentares e de baixo rendimento em termos produtivos e retorno monetário (INE, 2011). Segundo Sitoe (2005) além da atividade agrícola, o produtor rural tem diversificado a produção recorrendo assim a atividades agro-silvo-pecuárias de pequena escala, com uma heterogeneidade de atividades econômicas de geração de rendimentos dentro das famílias.

Para FAO (2015), Sitole (2005), constituem elementos de dinâmica que devem ser considerados na análise do setor agrário em Moçambique quais sejam: o não uso de pacotes tecnológicos agrícolas melhorados; as desigualdades no acesso e utilização da terra; fraca concentração de infraestruturas nas zonas prioritárias; o fraco acesso ao crédito, aos mercados de insumos e fatores e o fraco apoio financeiro aos produtores.

\section{Produção e comercialização do milho em Moçambique}

A produção do milho em Moçambique é considerada como uma prática tradicional, isso se deve pela relevância que a cultura representa para as famílias e por ser considerada como principal fonte de garantia na segurança alimentar e na geração de renda. A maior parte da produção da cultura vem da região centro do país especificamente nas províncias de Manica e Tete (JASSE, 2013).

Em Moçambique existem dois tipos de produtores de milho: produtor de milho de subsistência alimentar, aquele que apenas produz o que vai consumir; e o produtor de excedentes, aquele que tradicionalmente produz mais do que a sua necessidade de consumo e vende o excedente de produção de acordo com as suas necessidades e preços de mercado. A maioria dos agricultores utiliza apenas ferramentas básicas como enxadas para a preparação do solo, porém alguns, mais capacitados financeiramente, alugam trator e charrua a agentes locais ou associações de produtores para lavrar o solo (TIA, 2008; JASSE, 2013).

Segundo a África Digital (2017), o Governo de Moçambique junto ao Ministério de Ciência Tecnologia e Ensino Técnico Profissional vem envergando esforços com intuito de aumentar os níveis de produção de milho quer em termos qualitativos e quantitativos, através da transferência de tecnologias e boas práticas que culminem com aumento de produção e produtividade (Tabela 1). 
Tabela 1. Produção do milho em Moçambique entre os anos de 2006/2011.

\begin{tabular}{lccccccc}
\hline $\begin{array}{c}\text { Produção do } \\
\text { milho }\end{array}$ & Unid & 2006 & 2007 & 2008 & 2009 & 2010 & 2011 \\
\hline Área Colhida & ha & 1.664 .000 & 1.441 .000 & 1.480 .00 & 1.612 .000 & 1.573 .000 & 1.617 .380 \\
Produção & $\mathrm{t}$ & 1.417 .800 & 1.582 .000 & 1.676 .000 & 1.932 .000 & 1.878 .000 & 2.090 .790 \\
& & & & & & & \\
Produtividade & $\mathrm{Kg} / \mathrm{ha}$ & 852 & 1.097 & 1.132 & 1.198 & 1.193 & 1.292 \\
\hline \multicolumn{7}{c}{ Fonte: adaptado do Jasse (2013) da FAOSTAT }
\end{tabular}

Os dados da produção do milho entre as os anos de 2012 até 2018 ainda não estão disponíveis, eis a razão de aparecerem quantidades produzidas entre 2006/2011. Na Tabela entre os anos de 2006 a 2011 houve uma tendência crescente na área colhida, produção e mesmo na produtividade. A tendência crescente resultada em incentivos que o Governo de Moçambique vem realizando para impulsionar e revitalizar a produção do milho, focalizando-se mais no bem estar social do pequeno produtor.

A comercialização do milho é feita em todo território nacional por ser uma cultura de subsistência e geração de renda para o produtor rural. A região central do país composta pelas províncias de Manica, Tete, Sofala e Quelimane é a que detém maior fração de produção, garantindo a exportação para os países vizinhos, como Zâmbia e Malawi (INE, 2011; JASSE 2013).

A cadeia de valor do milho é composta por vendedores ambulantes, varejistas, atacadistas, intermediários e agroindústrias ou estabelecimento de processamento do milho na produção de farinha, bolachas, ração e outros subprodutos. Os estabelecimentos industriais adquirem o milho para 0 processamento e posteriormente fazem a distribuição dos produtos já processados dentro do país e de forma regional (exportação para os países vizinhos). Para Jasse (2013), Zidora (2015), a estratégia para aquisição do milho feita pelos estabelecimentos é em regime de contratos. Para além dos estabelecimentos industriais, existem organizações não governamentais como o Programa Mundial de Alimentação que compra o milho e outras culturas diretamente das associações de produtores.

\section{PROCEDIMENTO METODOLÓGICO}

Quanto ao procedimento metodológico da pesquisa foi realizada a revisão bibliográfica, que segundo Gil (2009), é uma pesquisa construída com base no material ou literatura existente como livros e artigos. Quanto aos objetivos, foi descritiva e explicativa, pois segundo o mesmo autor, pesquisas que abordam aspetos descritivos têm a sua relevância em fazer a descrição das características de uma determinada população ou fenômeno, cujo intuito é estabelecer uma relação entre as variáveis em estudo; a explicativa tem a sua relevância em explicar os possíveis fatores que dão origem ou contribuem significativamente para a ocorrência dos fenômenos em relação ao objeto de estudo. Quanto à abordagem, a pesquisa é qualitativa.

A pesquisa foi realizada com os produtores na região sul do país, nas províncias de Maputo, gaza e na província de Manica que se localiza na região 
centro. Para agregar valor à pesquisa, contou-se com uso de dados primários, obtidos por questionário aplicado a 107 produtores de milho das zonas rurais em Moçambique, e estava dividido em quatro partes: 1) Informação do produtor; 2) Informação da propriedade; 3) Informação da comercialização agrícola e 4) Análise de estratégia de hedge. A seleção da amostra para a pesquisa obedeceu o critério da amostragem não probabística por julgamento e/ou intenção, que segundo Oliveira; De Almeida; Barbosa (2012) e Barbetta (2011), afirmam que se usa quando o pesquisador possui informação prévia sobre o grupo alvo da pesquisa, o que the possibilita a escolha deliberada de certos elementos para pertencer a amostra por julgar os mesmos representativos da população.

As variáveis usadas na pesquisa são as socioeconômicas relacionadas com ações coletivas e outras com os contratos na produção e comercialização do milho. Essas varáveis são: idade do produtor, escolaridade, se é membro de uma associação ou cooperativa, satisfação com o retorno financeiro, participação em algum segmento de milho, sexo, segmento participado na comercialização do milho, renda bruta, uso de contrato na comercialização, efetividade do contrato, via usada para comercializar o milho.

\section{BENEFÍCIOS DOS CONTRATOS E DS AÇÕES COLETIVAS AO PRODUTOR NA PRODUÇÃO E COMERCIALIZAÇÃO DO MILHO EM MOÇAMBIQUE}

Neste capítulo foi efetuada uma discussão sobre os resultados da pesquisa captados por consultas bibliográficas e dos dados primários coletados por meio de questionário aplicado aos produtores de milho das zonas rurais. Buscou-se também trazer à tona a relevância e os benefícios da adoção de ações coletivas e uso de contratos na produção e comercialização do milho.

Em relação ao sexo, notou-se na pesquisa que a produção do milho é feita majoritariamente por homens (67,3\% homens e apenas $32,7 \%$ mulheres). A razão que faz com que a produção seja dominado por homens segundo o TIA (2008), é devido ao próprio sistema familiar das províncias pesquisadas que é patrilinear, no qual o homem é o chefe e provedor do sustento da família e as mulheres dedicam-se a outras atividades relacionadas com a casa. Algumas mulheres da pesquisa são viúvas e por isso acabavam por assumir a atividade, para dar continuidade do sustento da família.

Em termos de escolaridade, 40,2\% dos entrevistados não possui nenhuma escolaridade, $25,2 \%$ possuem o primeiro grau incompleto, $23,4 \%$ o primeiro grau completo, e $11,2 \%$ possuíam ensino médio. Para a TIA (2008), a disparidade educacional em áreas rurais em Moçambique chega a ser algo relacionado com o estilo de vida e da precariedade rural, caracterizado por ausência de infraestruturas, educação, saúde e comunicação e também aspectos culturais.

No que diz respeito a ações coletivas, especificamente a adesão a uma associação de produtores ou cooperativas, observou-se que $69,2 \%$ dos produtores pertenciam a uma cooperativa e apenas $30,8 \%$ não pertencem a nenhuma cooperativa. A adesão em ações coletivas como em associações e cooperativas continua sendo um meio efetivo implementado pelos pequenos agricultores, visto que ela cria mecanismo para ter acesso aos mercados e reduzir transparência, responsabilização, vínculos aprimorados, parcerias e redes com o 
setor privado, governo e ONGs (MUGERWA; LEMMA, 2011).

Como vantagens das ações coletivas na produção do milho em Moçambique, verificou-se que os membros pertencentes a cooperativas ou a uma associação de produtores tinham facilidades de comercializar a sua produção para diversos segmentos agroindustriais (processamento de farinha de milho, fábricas de bolachas e ração), pois que estes cumpriam com as exigências requeridas pelas indústrias em termos qualitativos e quantitativos. Observou-se que $38,3 \%$ dos produtores estão ligados a um segmento de processamento do milho e os restantes $61,7 \%$ não estavam ligados a nenhum segmento,e vendem a sua produção em praças informais a preços menos favoráveis, fato que torna a atividade não viável sob o ponto vista econômico. Os produtores pertencentes a uma associação ou cooperativa possuem maior vantagem e facilidade de negociar com as agroindústrias e essa negociação era feita na base de um contrato formal. O resultado da pesquisa é corroborado pelo Ostrom (2007) afirmando que o resultado socialmente ótimo é alcançado se os envolvidos cooperam entre si, no qual ocorre a busca de uma interação recíproca, baseada em confiança mútua e reputação entre os agentes envolvidos na transação.

No que diz respeito a renda bruta proveniente da comercialização do milho, $34 \%$ dos produtores apresentaram uma renda bruta anual entre $\mathrm{R} \$ 388,00$ e $3.155,00 ; 27 \%$ entre $\mathrm{R} \$ 3.155,00$ e $5.922,00 ; 11 \%$ dos produtores uma renda entre $R \$ 5.922,00$ e $8.689,00,28 \%$ entre $R \$ 8.689,00$ a $14.223,00$. Na pesquisa os produtores alegaram que para além do rendimento estar relacionada com a área produzida, capacidade de produção e o preço de venda na comercialização, em simultâneo dependia por parte de uma ação coletiva ou cooperação, isto é, aqueles que tiveram maior renda bruta entre a faixa de $R \$ 8.689,00$ a $14.223,00$ eram os que produziam e comercializavam via contratos e em simultâneo, eram membros pertencentes a uma associação ou cooperativa de agricultores.

Assim, compreende-se que o efeito coletivo trouxe benefícios econômicos de grande relevância para os produtores de milho, os resultados da pesquisa em relação a este aspecto estão de acordo com os resultados de Bialoskorski (2007) e Schmidt (2010), os quais enaltecem a participação em ações coletivas dos agentes e a conexão com os benefícios de natureza econômica, uma vez que conseguem aceder recursos que a título individual seria difícil, gerando assim vantagens competitivas e ampliando o lucro disponível como um todo.

Outro aspecto benefício da ação coletiva aos produtores de milho foi em relação a satisfação retorno financeiro, constatou-se que devido a cooperação que existiam entre os produtores $54,2 \%$ dos pesquisados responderam que estavam satisfeitos pelo retorno financeiro da produção e comercialização do milho e 45,2\% responderam que não estavam satisfeitos. Segundo Ayer (1997),para os agricultores as ações coletivas constituem alternativas promissoras para melhorar o bem-estar social, econômico e financeiro, e em simultâneo torna a produção mais próxima a um ótimo de Pareto quando comparado com as decisões e ações de interesse individual.

Os produtores que se mostraram não satisfeitos pelo retorno foram aqueles que não estavam em cooperação e dependiam do mercado e dos intermediários para comercializar sua produção estando sujeitos a riscos de variações preços. A organização dos produtores em ações coletivas, isto é, associações e cooperativas agrega valor e aumenta os ganhos econômicos na 
atividade. Este resultado da pesquisa é corroborado por SENAR (2013), Magerwa e Lemmar (2011), que afirmam a ação coletiva como mecanismo de governança que torna a atividade produtiva do pequeno produtor eficiente, pois os ganhos auferidos são superiores quando comparados com os individuais.

Como na pesquisa haviam dois grupos de produtores: os que estavam produzindo a título individual sem vínculo com qualquer grupo de associados e outros organizados coletivamente em associações e cooperativas, observou-se que $86 \%$ dos produtores pertenciam a cooperativa ou associação mostraram interesse em adotar o uso contratos na produção e apenas $14 \%$ mostrou não ter interesse. Dos que responderam não a adoção de contratos justifica pelo fato de que os contratos oferecidos pelas indústrias não eram transparentes e eficientes, estando sujeitos a muitas assimetrias informacionais e alguma razão recaía sobre a liderança por esta não conseguir desempenhar a sua tarefa. Para Olson (1999), a liderança e confiança constituem elementos chaves para o sucesso de uma ação coletiva.

Os contratos agrícolas possuem certos elementos que estimulam as ações coletivas, e um dos fatores que encoraja a tais ações tem sido a homogeneidade dos grupos que pode ser em termos étnicos assim como econômicos (BAUMANN, 2000). Por outra, a existência de muitos produtores rurais engajados na produção faz com que as empresas ou agroindustrias atendam a alguma forma de organização ou cooperativa para coordenar a produção. A FAO (2001), Shepherd (2013), apontam algumas vantagens de contratos agrícolas, entre eles na provisão de insumos e serviços produtivos; acesso ao crédito; acesso à tecnologia apropriada; acesso a transferência de habilidades; redução de risco de preços e criação de mecanismos que facilitam o acesso a mercados.

Na pesquisa $59,8 \%$ dos produtores não usavam contratos na comercialização, e apenas $40,2 \%$ usavam. Nota-se que a maioria não usava contratos porque alegavam que estes beneficiavam os compradores e não os produtores. Este aspecto não benéfico dos contratos que penalizava os produtores era devido a ações oportunistas por parte dos contratantes por esses não serem completos. Williamson (1991) faz um alerta sobre os contratos elaborados por não serem completos, originando assim o oportunismo entre os agentes envolvidos numa transação em querer aproveitar-se ou ter mais ganho na transação em detrimento do outro. Para além do oportunismo, FAO (2001) aponta como causas da não adesão de contratos aos produtores a manipulação de cotas e especificação de qualidade; corrupção; domínio dos monopólios.

Os produtores que aderiram ao uso de contratos tinham conhecimentos sobre os mesmos e mostravam ter mais benefícios na produção e comercialização. A ideia dos benefícios do uso de contratos na produção e comercialização é corroborada por Birthal (2000) que afirma que o uso de contratos naagricultura serve como um mercado seguro para os produtos à sua porta, reduzindo os custos de comercialização e transação e também o risco de preço. A disponibilidade de um mercado seguro também atua como um incentivo aos agricultores para usar insumos de qualidade, adotar tecnologias melhoradas e ampliar seus sistemas de produção.

A adesão de uma produção subcontratada aos produtores de milho servia elevando assim os benefícios econômicos, visto que a atividade agrícola no geral 
sofre efeitos diretos das condições climáticas assim como a sazonalidade da produção e constantes variações de preços no mercado.

Tabela 2. Característica de contrato em relação à definição do preço pago pela saca de milho

\begin{tabular}{lll} 
& Frequência & Percentagem \\
\hline Preço fixo & 95 & 88,8 \\
Cotação relacionada ao mercado & 3 & 2,8 \\
Preço variável & 9 & 8,4 \\
Total & 107 & 100,0 \\
\hline
\end{tabular}

Fonte: resultados da pesquisa

A observar a Tabela 2 que $88.8 \%$ dos produtores tinham por característica um contrato cotado a preço fixo, que era negociado levando em consideração os custos de produção arcados pelo produtor, de modo que este não saísse a perder. Outros $8,4 \%$ tinham um contrato em que o preço é variável mas muitas vezes esses contratos eram informais, tendo as suas críticas por parte dos produtores, pois que os penalizavam bastante e eram feitos por intermediários contratados pelas empresas que processavam o milho. Por fim, 2,8\% dependiam da cotação do mercado, mas isso era também acordado logo na elaboração, mas poucos aderiam porque tinham uma semelhança com os contratos baseados em preços variáveis. No que cerne a realidade moçambicana sobre a produção e comercialização do milho foi possível constatar no campo que cada contrato acima mencionado constituía para os produtores uma estratégia para a gestão dos riscos de preços, visto que o preço de venda do milho não compensava os custos da produção. A estratégia da comercialização do milho com uso de contratos é corroborado pelo Hull (2005) e Marques et al., (2006) que apontam a adoção de contratos agrícolas para minimizar riscos no preço de venda, visto que os produtos ou a produção agrícola assim como os preços de venda sofrem extremas variações.

\section{CONCLUSÃO}

O objetivo central da pesquisa foi analisar o papel dos contratos e das ações coletivas na produção e comercialização do milho em Moçambique, com ênfase na agricultura familiar. Ficou evidente que os contratos e as ações coletivas desempenham um papel crucial na produção e comercialização do milho, pois que os produtores agregam valor à atividade e, em simultâneo obtém ganhos coletivos de natureza econômica o que em nível individual era difícil.

O uso de contratos e das ações coletivas servem como elo motivacional aos produtores de milho, porque conseguem ter acesso aos mercados de insumos, acesso ao crédito, produção garantida em melhores condições qualitativos e quantitativos. Os produtores organizados em associações e cooperativas conseguem vender a sua produção para as grandes companhias no regime de contrato a preços satisfatórios, fato que melhora a sua condição social sobre o bem estar e uma qualidade de vida digna. $O$ acesso ao contrato depende por outro lado do estado organizacional dos produtores, sendo mais acessível para os que estão integrados em associações e cooperativas. A maior renda bruta na produção e comercialização do milho foi obtida para os produtores que estão ligados a ações coletivas e ao uso de contratos. 


\title{
The role of contracts and collective actions in the production and commercialization of corn in Mozambique
}

\begin{abstract}
The main objective of the research was to analyze the role of contracts and collective actions in the production and commercialization of maize in Mozambique. Methodologically the research was qualitative and counted on the use of secondary data (literature review) and also primary data and had a sample of 107 corn farmers from rural areas. The objective was explanatory and descriptive. The results of the research showed that the use of collective contracts and actions constitute efficient producer structures because they added value to the production and collective benefits of an economic nature when compared to an individual. The gross income from corn production was higher in producers who were organized in collective actions and those who traded via contracts. Collective actions and the use of contracts create access to producers to new markets, credit and aggregation of value to production.
\end{abstract}

KEY WORDS: collective actions, corn production and marketing contracts. 


\section{REFERÊNCIAS}

AFRICA DIGITAL. Moçambique quer aumentar a produção de arroz, trigo e milho no vale de Zambeze. Disponívelem:

$<$ https://africa21digital.com/2017/07/31/mocambiquequeraumentarproducaodea rroztrigoemilhonovaledozambeze $>$. Acessoem: 10/11/2017.

AFRICAN DEVELOPMENT BANK (ADB). African development fund.Agriculture and rural development sector.bank group policy . January 2000. disponível em:<https://www.afdb.org/fileadmin/uploads/afdb/documents/policydocuments/10000032-en-agriculture-and-rural-development-sector-bank-grouppolicy-final-version.pdf>. Acesso: 07/07/17.

ALLEN, D. W.; LUECK, D.The nature of the farm.Contracts, risk, and organization in agriculture. London, England. 2002. Disponívelem:

<base.dnsgb.com.ua/files/.../Agriculture/...Agriculture/The-Nature-of-the-FarmContracts $>$.Acessoem: 16/01/18.

ALLEN, D. W.; LUECK, D. Agricultural contracts.Netherlands. 2005.

AYER, H. W. Grass Roots collective action: agricultural opportunities.Journal of agricultural and resources economics,Milwaukee, v. 22, n.1, p.1-11, Jul. 1997.

BARBETTA, P. A. Estatística aplicada a Ciências Sociais. 7. Ed., Florianópolis: Editora UFSC. 2011.

BIRTHAL, P. S. Making contract farming work in smallholder agriculture. New Dheli.National Centre for Agricultural Economics and Policy Research.16p. 2000.

BANCO MUNDIAL. 2016. Disponível em:

<http://www.worldbank.org/pt/country/mozambique/overview>. Acesso em: 15/03/17.

BAUMANN, P. Equity and Efficiency in Contract Farming Schemes: The Experience of Agricultural tree Crops. Working Paper 139. Overseas Development Institute, 111 Westminster Bridge Road London SE1 7JD UK. 2000. Disponível em: $<$ https://www.odi.org/resources/docs/2730.pd>. Acesso em: 13/08/17.

BIALOSKORSKI, S. Um ensaio sobre desempenho econômico e participação em 2007 - Impressa em março 2007. 
FIANI, R. Arranjos institucionais e desenvolvimento: o papel da coordenação em estruturas híbridas. IPEA. Rio de Janeiro. Março de 2013.

FAO. ContractfarmingPartnerships for growth. Rome. 2001. Disponível em: $<$ www.fao.org/docrep/014/y0937e/y0937e00.pdf $>$. Acesso em: 10/10/17.

FAO. Programa da FAO em Moçambique No âmbito do programa das nações unidas delivering as one. Moçambique 2012 - 2015. 2011. Disponível em:

<ftp://ftp.fao.org/osd/CPF/Countries/Mozambique/CPFbrochure-por_MOZ_20122015.pdf>. Acesso em: 29/05/17.

FAO. The state of food and agriculture.Social protection and agriculture: Braking the cicle or rural poverty. Rome.2015. Disponivel em: $<w w w . f a o . o r g / 3 / a-$ i4910e.pdf >. Acesso em: 02/04/18.

FARINA, E. M. M. Q; AZEVEDO, P. F.; SAES, M. S. M. Competitividade: mercado, Estado e organizações. São Paulo: Singular, 1997. 286 p.

GIL, A. C. Como elaborar projetos de pesquisa. Quarta edição, décima segunda impressão, Editora Atlas. São Paulo. 2009.

GRANOVETTER, M. The strengeth of weak ties: a network theory revised. Sociologicaltheory, Vol. 1, pp. 201-233. 1983.

HULL. John C. Fundamentos dos mercados futuros e de opções. 4. ed. São Paulo: Bolsa de Mercadorias e Futuros, 2005.

INSTITUTO NACIONAL DE ESTATÍ́STICA (INE). Censo Agro-pecuário: Resultados definitivos. Maputo, Moçambique, 2011.Disponível em: $<$ http://www.ine.gov.mz/>. Acesso em: 02/04/13.

MARQUES, P.V.; MELLO, P. C.; MARTINES, J. G. Mercados Futuros e de Opções Agropecuárias. Piracicaba, S.P, Departamento de Economia, Administração e Sociologia da Esalq/USP, Série Didática no D-129, 2006.

MINISTÉRIO DE AGRICULTURA E SEGURANÇA ALIMENTAR (MASA). Oportunidade de investimento em no agronegócio em Moçambique. Abril/2015. Disponível em: $<$ http://www.fao.org/fileadmin/templates/est/investment/mozambique/cepagri masa_abril fao agri investiment.pdf $>$. Acesso em: 02/01/18. 
<https://www.cplp.org/Admin/Public/DWSDownload.aspx?File...MASA...pd>.

Acesso em : $04 / 07 / 17$.

JASSE, A. Cadeias de valor de cereais e oleaginosas. Relatório de consultoria do estudo de cadeias de valor de cereais e oleaginosas. Província de Sofala - Distrito de Nhamatanda. Moçambique. 2013.

MUGERWA, W.K.; LEMMA, T. Develping farms contract systems in Uganda.2011. Disponível em: <http://www.world-agriculture.net/article/developing-contractfarming-systems-in-uganda>. Acesso em: 20/10/ 2017.

KUNKEL, P. L.; ATTORNEYS, J. A. P.; MOOTY, G. P. Agricultural Production Contracts. University of Minnesota extension. Agricultural Business Management. FARM LEGAL SERIES. June 2015.

OSTROM, E. Collective Action and Local Development Processes.2007.

OLSON, M. A lógica da ação coletiva - Introdução, Cap. 1; Cap. 2. p. 13 - 77). 1999.

OLIVEIRA, K. M.; DE ALMEIDA, K. L.; BARBOSA, T. L. Amostragens probabilísticas e não probabilísticas: técnicas e aplicações na determinação de amostras. 2012. Disponível em: $<$ files.wendelandrade.webnode.com.br/.../Amostragens\%20probabilística\%20e\%2 0>. Acesso em: 11/05/2015.

PREZOTTO, L. L. Agroindústria Familiar regulação e acesso ao mercado. Primeira edição, Apoio da SENAR. Termo de cooperação técnica financeira 002/2016 SENAR/ CONTAG. Brasília/DF. 2016.

RIBEIRO, M. C. P.; ROCHA JR, W. F.; CZELUSNIAK, V. A. Mecanismos jurídicos e econômicos para transferência de tecnologia: um estudo de caso. São Paulo, Revista de Direto GV, v.13, n.1, p. 49-68, 2017.

RURAL LIVELIHOOD DEVELOPMENT PROGRAMME - RLDC. Contract farming in Tanzania's central corridor. Lessons from the rural livelihood Development Programe in Tanzania. 2016.

SERVIÇO NACIONAL DE APRENDIZAGEM RURAL - SENAR. Associações Rurais Práticas associativistas, características e formalizações. Brasília. 2011. 
SITOE, T. A. Agricultura familiar em Moçambique - Estratégias de desenvolvimento Sustentável. Faculdade de Agronomia e de Engenharia Florestal - UEM. Maputo. 2005.

SCHMIDT, C. M. Tese de doutorado - Criação e apropriação de valor no sistema agroindustrial do vinho do vale dos vinhedos. São Paulo. 2010.

SHEPHERD, A. W. An introduction to contract farming. Technical Centre for Agricultural and Rural Cooperation (ACP- EU). Abidjan - Costa de Marfim. 8p. 2013.

TRABALHO DE INQUÉRITO AGRÍCOLA (TIA). Maputo-Moçambique. 2008.

USAID. Custo econômico do conflito em Moçambique avaliação do impacto econômico do conflito no setor do turismo.Maputo- Moçambique.

2015.Diponívelem: <speed-test.co.s79942.gridserver.com/.../2014-SPEED-Report005-Economic-cost-of-r>. Acessoem: 03/09/16.

VAVRA, P. Role, Usage and Motivation for Contracting in Agriculture. OECD food, agriculture and fisheries working pappers N. 16. 2009.

WILLIAMSON, O. Comparative Economic Organization. The Analysis of Discrete Structural Alternatives. Administrative Science Quarterly, Vol. 36 (2), p. 269-296, 1991.

ZIDORA, CÉSAR, B, M. Dissertação de Mestrado - Estratégias de gerenciamento de riscos de preços na comercialização do milho em grãos na zonas rurais de Moçambique. Dissertação de Mestrado - Universidade Federal de Goiás. Goiânia. 2015.

ZYLBERSZTAJN, D. Papel dos contratos na coordenação agro-industrial: um olhar além dos mercados. RER, vol. 43, p. 385-420, Rio do Janeiro. Jul/Set 2005.

ZYLBERSZTAJN, D. Estruturas de Governança e Coordenação do Agribusiness: Uma Aplicação da Nova Economia das Instituições. USP. São Paulo. 1995. 
Recebido: 17 jun. 2018.

Aprovado: 19 ago. 2018

DOI: $10.3895 /$ rbpd.v7n4.8745

Como citar: ZIDORA, C. B. M.; ROCHA JR. W. F.; RIBEIRO, M. C. P.; SILVA, D. L.; OLIVEIRA, H. F. O

papel dos contratos e das ações coletivas na produção e comercialização do milho em Moçambique. $\mathbf{R}$. bras. Planej. Desenv.,Curitiba, v. 7, n. 4, p. 461-478, set./dez. 2018. Disponível em:

$<$ https://periodicos.utfpr.edu.br/rbpd>. Acesso em: XXX.

Correspondência:

Weimar Freire da Rocha Jr

R. da Faculdade, 645 - Jardim La Salle, Toledo - PR, Brasil

Direito autoral: Este artigo está licenciado sob os termos da Licença CreativeCommons-Atribuição 4.0

Internacional.

(c) (i) 